\title{
PERANCANGAN SISTEM MONITORING TEGANGAN PIEZOELEKTRIK UNTUK PENGISIAN BATERAI BERBASIS BLUETHOOTH
}

\author{
Ashhab Aghnil Hakim ${ }^{1}$, Esa Apriaskar ${ }^{2}$, Djunaidi $^{3}$ \\ ${ }^{1,2,3}$ Program Studi S1 Teknik Elektro, Jurusan Teknik Elektro Fakultas Teknik Universitas Negeri Semarang \\ Kampus Sekaran, Gunungpati, Semarang, 50229, Indonesia \\ ashhabhakim99@students.unnes.ac.id ${ }^{l}$, esa.apriaskar@mail.unnes.ac.id ${ }^{2}$, djunaidi@mail.unnes.ac.id $^{3}$
}

\begin{abstract}
Electrical energy has become one of the basic needs at this time. The more population, the more electricity consumption is needed. so it takes a lot of innovation to support those needs. Energy harvesting system is one of them, by using piezoelectricity, we can harvest electrical energy. This tool works by changing the kinetic energy of the human footing which is then converted to produce electrical energy. In use, when it runs normally on this prototype the influence of the elasticity of the materials present in this prototype will cause vibrations and give effect to the piezoelectric sensor. Then the vibrations detected by piezoelectric will respond to the kinetic energy produced. This kinetic energy is produced from human footing which can be converted into other forms of energy according to energy conversion. Energy utilization is carried out by storing the energy output from the piezoelectric into the battery (recharge), which then by using a voltage sensor and Bluetooth module $\mathrm{HC}-05$ will be monitored and data will be sent to the cellphone so that the piezoelectric output voltage can be recorded and monitored.
\end{abstract}

Keywords : Piezoelectric, Battery, Voltage Sensor, Bluetooth HC05.

\begin{abstract}
Abstrak- Energi listrik sudah menjadi salah satu kebutuhan pokok saat ini. Semakin banyak jumlah penduduk maka semakin banyak pula konsumsi listrik yang dibutuhkan. sehingga dibutuhkan banyak inovasi untuk menyokong kebutuhan tersebut. Sistem pemanen energi merupakan salah satunya, dengan menggunakan piezoelektrik kita dapat memanen energi listrik Cara kerja alat ni yaitu dengan mengubah energi kinetik dari pijakan manusia yang kemudian di konversi untuk menghasilkan energi listrik. Dalam penggunaannya, ketika berjalan normal di atas prototipe ini pengaruh sifat eleastisitas bahan yang ada pada prototipe ini akan menyebabkan getaran dan memberikan efek pada sensor piezoelektrik. Kemudian getaran yang dideteksi oleh piezoelektrik akan merespon energi kinetik yang dihasilkan. Energi kinetik ini dihasilkan dari pijakan manusia yang dapat dikonversi menjadi bentuk energi lain sesuai dengan konversi energi. Pemanfaatan energi dilakukan dengan menampung hasil energi dari piezoelektrik ke dalam baterai (recharge), yang kemudian dengan menggunakan sensor tegangan dan modul Bluetooth HC-05 akan dimonitoring dan data akan dikirim ke ponsel supaya tegangan output piezoelektrik dapat didata dan dimonitoring.
\end{abstract}

Kata kunci : Piezoelektrik, Baterai, Sensor Tegangan, Bluetooth HC-05.

Kata kunci- Android, Panel Surya, Arduino Uno, Bluetooth.

\section{Pendahuluan}

Energi merupakan suatu kebutuhan pokok dalam kehidupan manusia, dengan semakin menipisnya energi fosil di bumi ini karna sifatnya yang tak terbaharukan. Manusia mulai mencari energy baru dengan menciptakan suatu alat pemanen energy (energy harvesting). Piezoelektrik merupakan salah satu dari sekian banyaknya yang dapat diaplikasikan untuk memanen energy, cara kerjanya yaitu dengan mengubah energy kinetik yang dihasilkan dari pijakan manusia menjadi energi listrik

Pemanfaatan piezoelektrik sebagai generator merupakan suatu upaya mendapatkan energi listrik yang merujuk pada konsep harvesting energy yang hal ini merujuk pada pengembangan piezoelektrik sebagai generator yang mengubah getaran yang dihasilkan mobil listrik menjadi energi listrik yang dapat digunakan pada piranti elektronik berdaya rendah (low power devices). Getaran merupakan salah satu bentuk energi mekanik yang paling sering dijumpai di mobil listrik. Banyak sumber energi getaran yang tersedia dan dimanfaatkan menjadi dasar pembuatan catu daya mikro dengan menggunakan piezoelektrik. Dari hasil pengujian menunjukkan bahwa ada pengaruh terhadap pemberian besarnya tahanan beban pada piezoelektrik, semakin besar tahanan beban maka tegangannya juga semakin besar dan tahanan dibawah $20 \mathrm{~K} \Omega$ tidak ada arus yang mengalir. Piezoelektrik memiliki daya output yang kecil akan tetapi dengan nilai impedansi internal yang tinggi. Oleh karena penggunaan piezoelektrik sebagai generator memungkinkan untuk digunakan dalam teknologi pada bagian mobil listrik yang membutuhkan daya kecil [1].

Penelitian lain tentang piezoelectric [2] bahwa pijakan kaki manusia pada lantai yang sudah terpasang piezoelectric dibawahnya menjadi input energi mekanik untuk mendapatkan energi listrik dari lantai. Banyaknya energi listrik yang dapat dihasilkan lantai piezoelectric berbanding lurus dengan besar gaya yang diberikan pada lantai piezoelectric. Arus tertinggi yang didapatkan dari lantai yang dibuat akibat gaya mekanik yakni 938 mikro ampere dan arus terendah 464 mikro ampere. Sedangkan tegangan tertinggi yang didapat yakni 80 volt dan terendah 61 volt. Pemanfaatan energi dapat dilakukan dengan menampung hasil energi kedalam sebuah baterai sekunder(recharge) dengan memperhatikan kapasitas baterai dan intensitas penginjakan.

Pada penelitian lainnya [3] menganalisis gelombangan tegangan keluaran piezoelektrik sehingga dapat 
diliat bentuk gelombang yang menempelkan piezoelektrik pada dinding kemudian memukulkannya menggunakan silinder pemukul yang dipasang pada sebuah motor sehingga motor berputa, silinder pemukul akan mengenai piezoelektrik.hasil penelitian ini di mana tegangan yang dihasilkan oleh piezoelektri berpengaruh terhadap dimensi (luas penampang dan tebal) dari piezoelektrik,

Penelitian lain [4] bertujuan untuk membandingkan pengisian kapasitor oleh piezoelektrik dengan baterai. Metode peneltian berupa mengetuk sebuah piezoelektrik berdiameter 2,7 cm menggunakan jari tangan dengan frekuensi $30 \mathrm{bpm}, 60$ bpm, 90 bpm, 120 bpm, 150 bpm, dan 180 bpm untuk mengisi kapasitor sebesar 47 uF yang tegangannya diamati setiap 10 detik selama 90 detik. Ketukan 30, 60, 90, 120, 150, dan 180 bpm secara berturut - turut menghasilkan tegangan akhir kapasitor sebesar $575 \mathrm{mV}, 882 \mathrm{mV}, 980 \mathrm{mV}, 1337 \mathrm{mV}, 1383$ $\mathrm{mV}$, dan $1444 \mathrm{mV}$. Setelah itu, hubungan antara frekuensi ketukan dan tegangan akhir kapasitor dianalsisis untuk dibandingkan dengan pengisian kapasitor oleh baterai.

Pada Penelitian [5] memanfaatkan waste vibration energy dari gerakan kendaraan bermotor menggunakan polisi tidur piezoelektrik. Polisi tidur piezoelektrik yang dirancang pada penelitian terdiri atas sistem mekanik polisi tidur yang berfungsi menerima masukan dari tekanan kendaraan bermotor, sistem kantilever piezoelektrik sebagai komponen penghasil energi listrik dan sistem harvesting energy sebagai pemanen energi dari material piezoelektrik. Satu modul sistem terdiri dari rangkaian paralel piezoelektrik yang dihubungkan dengan buck konverter MB39C811. Sistem yang paling maksimal menghasilkan energi adalah rangkaian lima modul secara paralel. Polisi tidur piezoelektrik mampu menghasilkan daya listrik dengan masukan 60 kali lindasan kendaran bermotor sebesar 2.166mWh dengan efisiensi $2.87 \%$ dibandingkan dengan masukan manual.

\section{LANDASAN TEORI}

\section{Piezoelektrik}

Piezoelektrik merupakan suatu komponen elektronika yang materialnya memiliki kemampuan untuk dapat menghasilkan energy listrik ketika pada permukaan piezoelektrik diberikan tekanan mekanik. Piezoelektrik memiliki material yang tersusun atas molekul krustal, keramik, atau polimer yang apabila ndiberi tekanan dapat menghasilkan energy listrik, kemampuan inilah yang akan dimanfaatkan untuk memanen energy listrik.

Efek piezoelectric merupakan sebuah kemampuan suatu material untuk bergetar apabila diberikan tegangan pada material tersebut dan sebaliknya, apabila suatu material diberi tekanan maka material tersebut akan menghasilkan tegangan. Efek piezoelectric terjadi jika medan listrik tebentuk ketika material dikenai tekanan mekanik. Pada saat medan listrik melewati material, molekul yang terpolarisasi akan menyesuaikan dengan medan listrik, dihasilkan dipol yang terinduksi dengan molekul atau struktur kristal materi. Penyesuaian molekul akan mengakibatkan material berubah dimensi. Fenomena tersebut dikenal dengan electrostriction.
Besarnya konsentrasi muatan listrik yang terbentuk dari efek piezoelectric dapat dinyatakan dalam dua mode, yaitu charge mode dan voltage mode. Tegangan dan Arus yang dihasilkan piezoelectric berbanding lurus dengan gaya yang diberikan dan berbanding terbalik dengan luas penampang bidang.

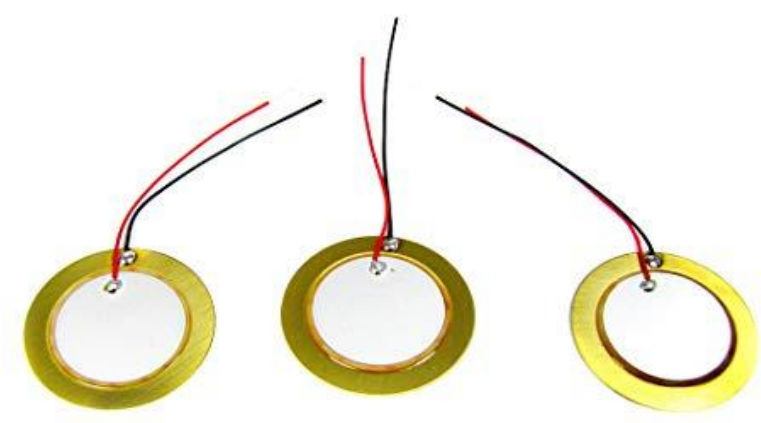

Gambar 1. Piezoelektrik

\section{Arduino Uno}

Arduino Uno merupakan sebuah board mikrokontroler berbasis Atmega328 yang memiliki 14 pin digital input/output diantaranya terdiri dari 6 pin input sebagai output PWM, 6 pin input analog, osilator kristal $16 \mathrm{MHz}$, koneksi USB, jack power, ICSP header, dan tombol reset. Untuk menggunakan arduino uno cukup dengan menghubungkan board arduino uno ke komputer dengan menggunakan kabel USB atau dari baterai untuk menjalankanya.

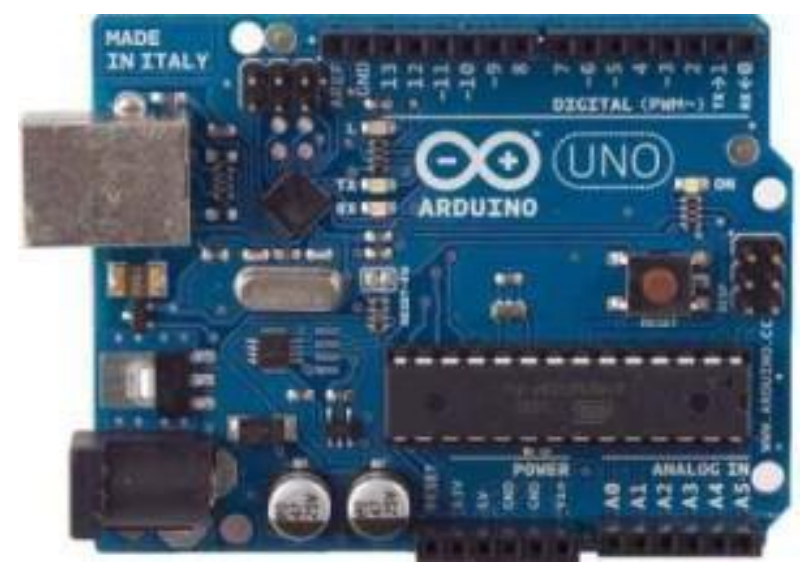

Gambar 2. Arduino Uno

\section{Sensor Tegangan}

Prinsip kerja modul sensor tegangan ini dapat membuat tegangan input mengurangi 5 kali dari tegangan asli. Sehingga, sensor hanya mampu membaca tegangan maksimal $25 \mathrm{~V}$ bila diinginkan Arduino analog input dengan tegangan $5 \mathrm{~V}$, dan jika untuk tegangan $3,3 \mathrm{~V}$, tegangan input harus tidak lebih dari $16.5 \mathrm{~V}$. 


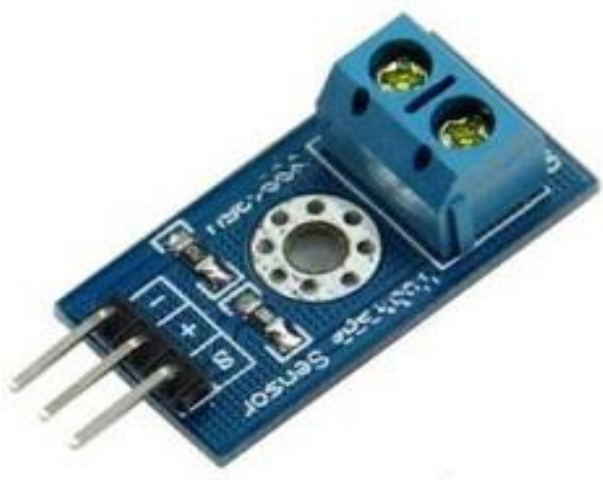

Gambar 3. Modul Sensor Tegangan

Cara mengukur tegangan pada modul piezoelektrik, modul tegangan ini dirangakai secara pararel dengan piezoelektrik.

\section{Baterai}

Baterai merupakan sebuah perangkat yang dapat mengubah energi kimia yang disimpannya menjadi energi Listrik yang dapat digunakan oleh suatu perangkat Elektronik. Baterai atau akkumulator adalah sebuah sel listrik dimana didalamnya berlangsung proses elektrokimia yang reversible (dapat berkebalikan) dengan efisiensinya yang tinggi. Yang dimaksud dengan reaksi elektrokimia reversible adalah didalam baterai dapat berlangsung proses pengubahan kimia menjadi tenaga listrik (proses pengosongan) dan sebaliknya dari tenaga listrik menjadi tenaga kimia (proses pengisian) dengan cara proses regenerasi dari elektroda - elektroda yang dipakai yaitu, dengan melewatkan arus listrik dalam arah polaritas yang berlawanan didalam sel.

\section{Modul Bluetooth HC-05}

Modul Bluetooth HC-05 adalah modul komunikasi nirkabel via bluetooth yang dimana beroperasi pada frekuensi $2.4 \mathrm{GHz}$ dengan pilihan dua mode konektivitas.Mode 1 berperan sebagai slave atau receiver data saja, mode 2 berperan sebagai master atau dapat bertindak sebagai transceiver.

Pengaplikasian komponen ini sangat cocok pada project elektronika dengan komunikasi nirkabel atau wireless antara lain aplikasi sistem kendali, monitoring, maupun gabungan keduanya.
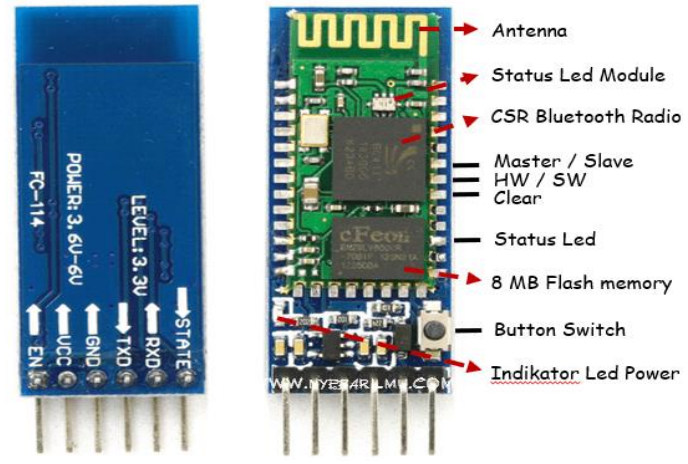

Gambar 4. Module Bluetooth HC-05

\section{METODE PENELITIAN}

\section{A. Analisa Kebutuhan Hardware dan Software}

Bahan dan peralatan yang dibutuhkan dalam pembuatan Sistem Monitoring Tegangan Piezoelektrik Untuk Pengisian Baterai Berbasis Bluetooth diantaranya Perangkat Keras (Hardware) berupa modul Piezoelektrik, ponsel android, Modul Bluetooth, Modul sensor tegangan, RTC, Arduino Uno, Kabel Jujmper, PCB, baterai, Rectifier. Serta perangkat lunak berupa Arduino IDE (Integrated Development Environment) dan Aplikasi Blueserial.

\section{B. Perancangan Sistem}

Secara umum sistem yang akan dibuat dapat digambarkan dengan Diagram Blok pada gambar 5. Alur kerja yang digambarkan dalam Blok Diagram Sistem adalah Konversi energy mekanik menjadi energy listrik saat Modul Piezoelektrik diberikan tekanan ataupun getaran yang kemudian tegangan keluaran dari modul piezoelektrik disearahkan terlebih dahulu oleh diode rectifier sebelum masuk ke baterai dan sensor tegangan, lalu mikrokontroler yaitu Arduino akan membaca data tegangan dan waktu pengambilan data oleh modul sensor dan Modul RTC tegangan kemudian dikirimkan ke android melalui modul Bluetooth HC-05.

Berikut gambaran umum system.

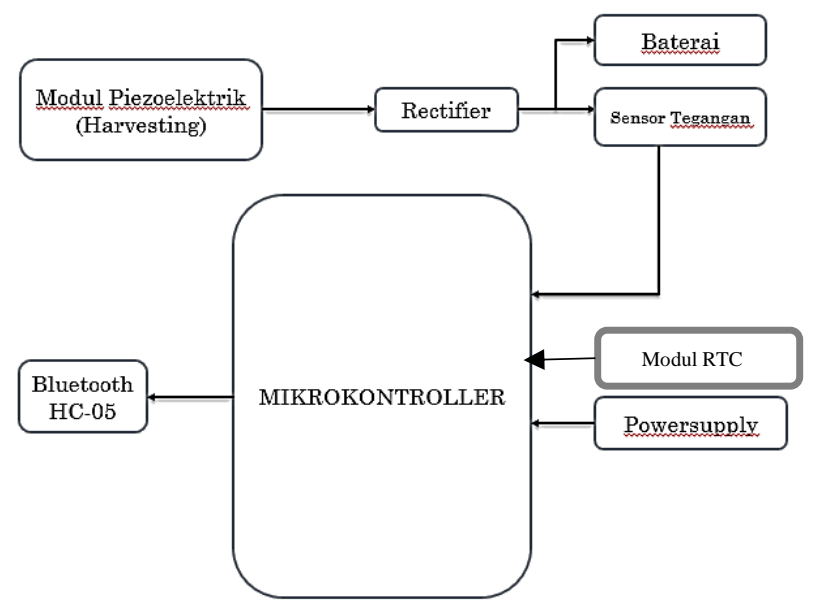

Gambar 5. Block Diagram Sistem

\section{Konfigurasi hardware}

Konfigurasi Hardware secara keseluruhan dapat digambarkan seperti gambar berikut: 


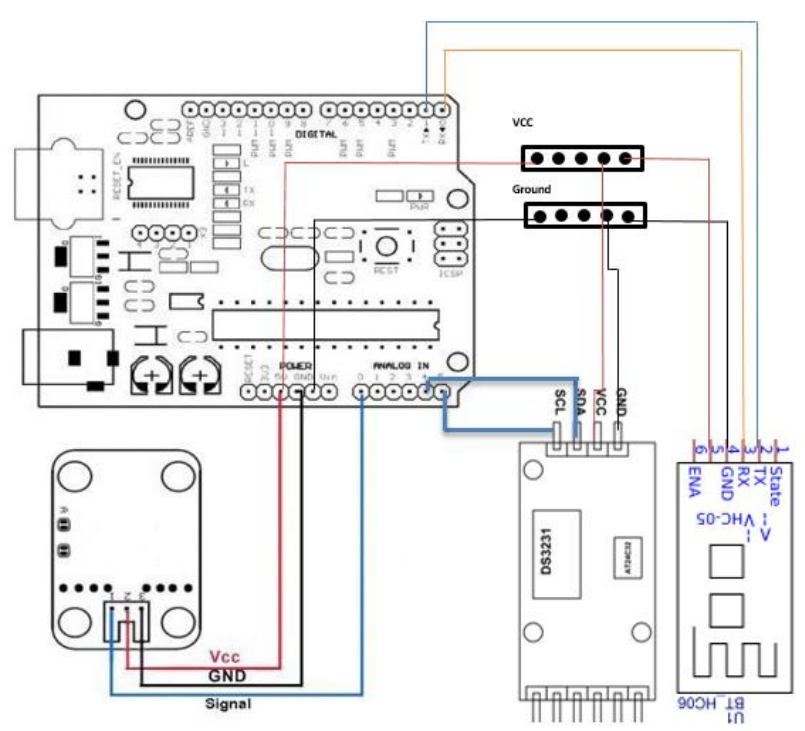

Gambar 6. Konfigurasi Hardware Secara Keseluruhan

Arduino UNO mendapat sumber tegangan dari baterai 9V. RX dan TX modul Bluetooth dihubungkan ke TX dan RX Arduino UNO dan mengambil sumber tegangan (5V) dari Arduino UNO. Data modul tegangan dihubungkan dengan PIN analog IN0 dan mengambil sumber tegangan 5v pada Arduino.sedangkan Pin SDA dan SCL RTC mendapatkan Pin analog IN4 dan IN5 dan juga mengambil sumber tegangan 5v dari Arduino.

\section{Perancangan Mekanik Piezoelektrik}

Modul yang saya rancang merupakan perbaikan dari alat yang pernah dibuat. Dengan ditambahkan beberapa komponen dan memodifikasi pada susunan sistem dengan tujuan untuk memperbaiki dan menyempurnakan alat tersebut.

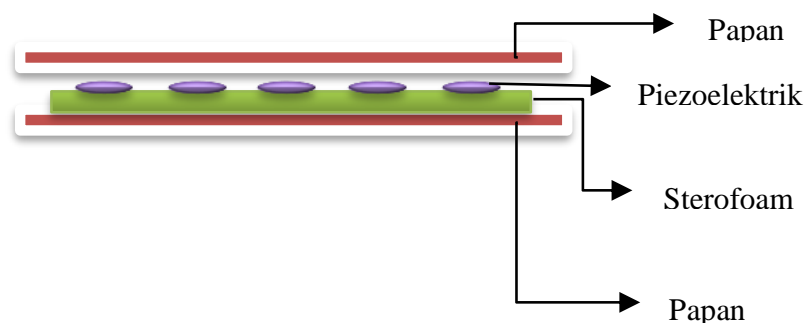

Gambar 7. Desain Mekanik Piezoelekterik

Perancangan Mekanik Piezoelektrik diatas dirancang dengan menempatkan Sterofoam di bagian bawah Piezoelektrik supaya piezoelektrik tidak mudah rusak dan juga berguna untuk memaksimalkan hasil getaran piezoelektrik.

Pembuatan dan perancangan pada prototipe dengan pemanfaatan sensor piezoelektrik sebagai penghasil sumber energi terbagi dua, yaitu dengan penyusunan secara seri dan paralel. Perancangan prototipe dengan menyusun beberapa sensor piezoelektrik yang satu dengan yang lain untuk membentuk suatu generator pembangkit yang akan memberikan tegangan dan arus dengan menempelkannya pada gabus sebagai alas penompang agar sensor tidak rusak ketika di beri beban.

Namun karna tujuan kita adalah menggunakan piezoelektrik untuk mencharging baterai maka kita membutuhkan tegangan yang cukup sehingga piezoelektrik dirangkai secara pararel. diketahui jumlah total tegangan yang dihasilkan pada rangkaian Pararel adalah penjumlahan tegangan yang dihasilkan tiap sensor piezoelektrik dan jumlah total arus adalah sama dengan arus yang dihasilkan tiap sensor piezoelektrik

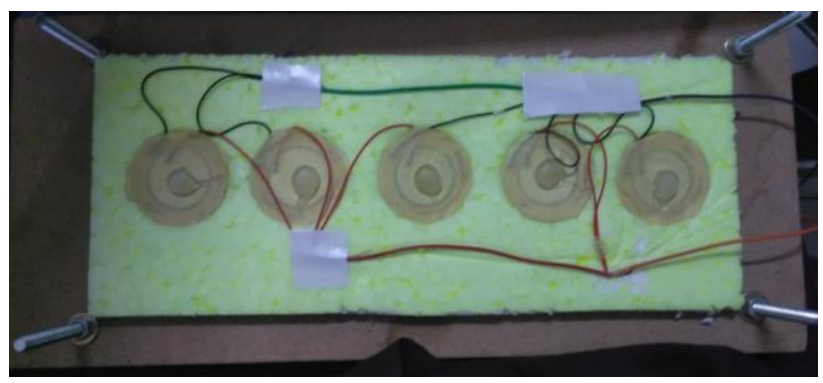

Gambar 8. Rangkaian Piezoelektrik Secara Pararel

\section{E. Pembuatan alat}

Konfigurasi hardware keseluruhan pada perancangan hardware direalisasikan pada alat sebenarnya.

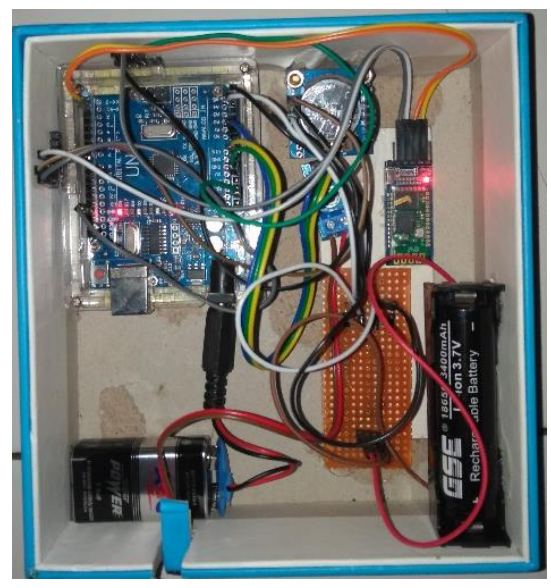

Gambar 9.Rangkaian Keseluruhan Alat

Rangkaian keseluruhan alat yang dibuat yang terdiri dari Arduino Uno, Modul RTC, Bluetooth modul, Sensor Tegangan, Baterai Adaptor 9V, dan Terminal kabel.

\section{F. Pembuatan Program Arduino}

Program arduino ditulis dengan bahasa C menggunakan software Arduino IDE (Integrated Development Environment). Pada Arduino IDE terdapat 2 fungsi yaitu :

1. Fungsi void setup() 
Pada fungsi void setup() ini akan ditetapkan tipe data yang masuk, pin yang digunakan, juga menetapkan pin-pin tersebut sebagai output, seperti pada gambar berikut :

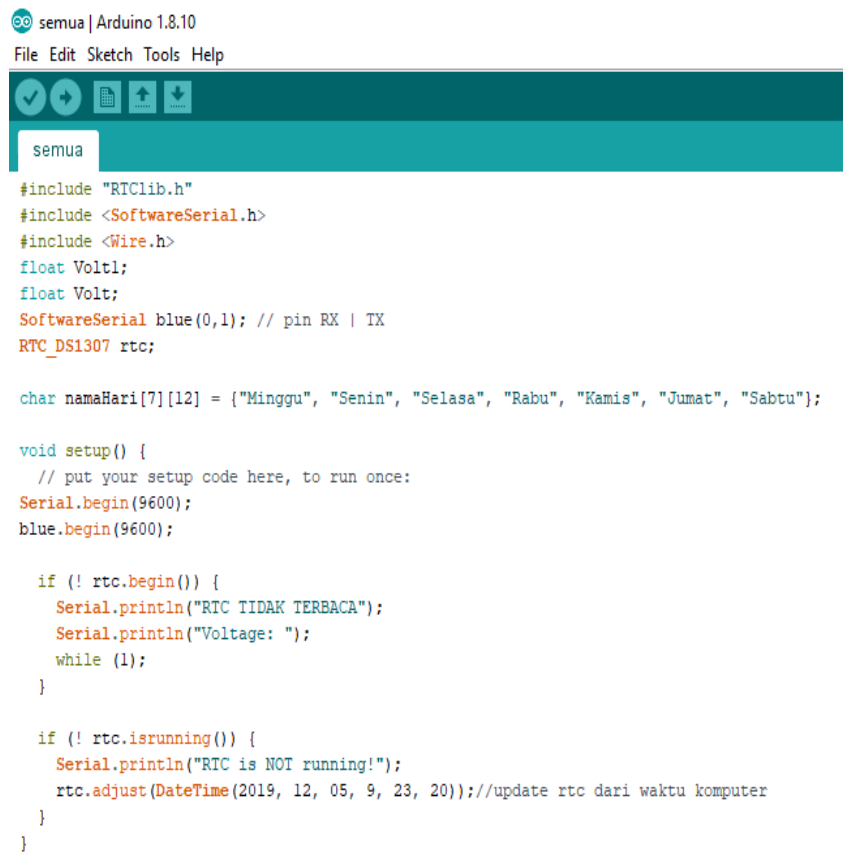

Gambar 10. Fungsi void setup() pada Arduino

2. Fungsi Program Utama

Program utama adalah fungsi looping jika mendapat input data, source code pada Arduino IDE seperti berikut :

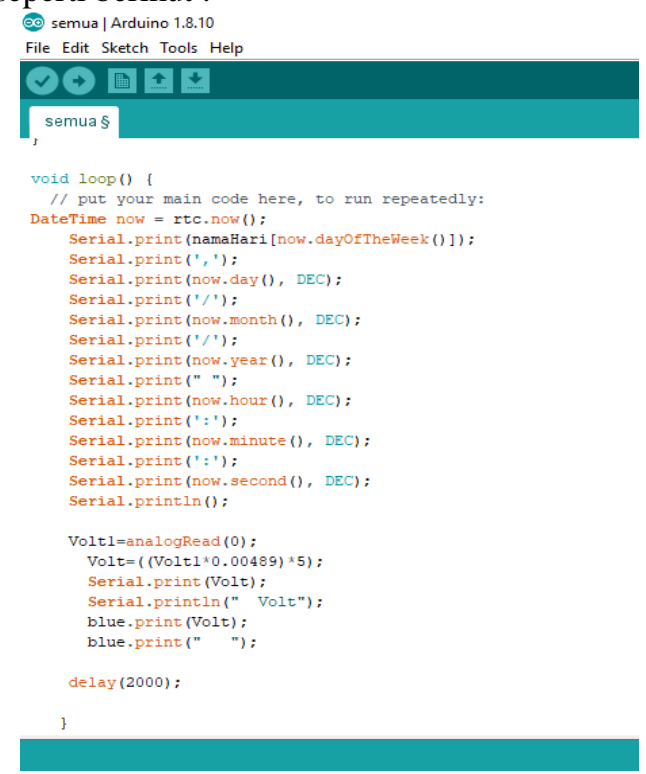

Gambar 11. Tampilan Program Utama Arduino IV ANALISA DAN PEMBAHASAN

Pengujian dan analisis sistem meliputi dua macam yaitu pengujian rangkaian monitoring tegangan piezoelektrik dan pengujian sistem piezoelectric yang telah dibuat. Pada
Pengujian Sistem Monitoring digunakan software Blueserial untuk menyambungkan dengan modul Bluetooth HC-05 supaya dapat membaca data tegangan pada ponsel android.

1. Pengujian Mekanik Piezoelektrik dan Sistem Monitoring Pada pengujian pembaca tegangan dilakukan pengambilan data dari rangkaian sensor tegangan yang telah dibuat yang kemudian dicatat waktu pengambilan datanya oleh RTC dan dikirim oleh modul Bluetooth HC-05. Rangkaian tersebut berfungsi untuk membaca tegangan yang dihasilkan piezoelectric setelah melalui rectifier.

Sebelum pengujian dilakukan instal terlebih dahulu software blueserial pada ponsel android setelah itu hubungkan Bluetooth ponsel dengan modul Bluetooth HC05 lalu buka aplikasi yang sudah diinstal di ponsel kemudian hubungkan dengan Bluetooth HC-05 maka dengan otomatis akan menampilkan data tegangan dari piezoelektrik.

Berikut contoh data yang sudah diambil pada aplikasi blueserial.

\section{Blueserial app}

\begin{tabular}{|c|c|c|}
\hline Disconnect & Clear Input & $\begin{array}{l}\square \text { Scroll } \\
\checkmark \text { Read }\end{array}$ \\
\hline $\begin{array}{l}\text { Kamis, } 5 / 12 / 2019 \\
1.05 \text { Volt } \\
\text { Kamis, } 5 / 12 / 2019 \\
0.00 \text { Volt } \\
\text { Kamis, } 5 / 12 / 2019 \\
2.32 \text { Volt } \\
\text { Kamis, } 5 / 12 / 2019 \\
0.00 \text { Volt } \\
\text { Kamis, } 5 / 12 / 2019 \\
3.67 \text { Volt } \\
\text { Kamis, } 5 / 12 / 2019 \\
2.27 \text { Volt } \\
\text { Kamis, } 5 / 12 / 2019 \\
0.00 \text { Volt } \\
\text { Kamis, } 5 / 12 / 2019 \\
0.22 \text { Volt } \\
\text { Kamis, } 5 / 12 / 2019 \\
0.00 \text { Volt } \\
\text { Kamis, } 5 / 12 / 2019 \\
0.00 \text { Volt } \\
\text { Kamis, } 5 / 12 / 2019 \\
6.92 \text { Volt } \\
\text { Kamis, } 5 / 12 / 2019 \\
0.20 \text { Volt }\end{array}$ & $\begin{array}{l}2: 44: 39 \\
2: 44: 41 \\
92: 44: 43 \\
92: 44: 45 \\
92: 44: 47 \\
92: 44: 49 \\
92: 44: 51 \\
92: 44: 53 \\
92: 44: 55 \\
92: 44: 57 \\
92: 44: 59 \\
92: 45: 1\end{array}$ & \\
\hline
\end{tabular}

Gambar 12. Monitoring data tegangan lewat ponsel

Lewat gambar diatas telah terbukti bahwa pengujian Mekanik Piezoelektrik dan system monitoring menggunakan Bluetooth $\mathrm{HC}-05$ berhasil dan data telah berhasil diambil dan dapat diketahui tegangan output dari piezoelektrik.

Berikut data yang didapatkan dari pengukuran rangkaian pembaca tegangan 


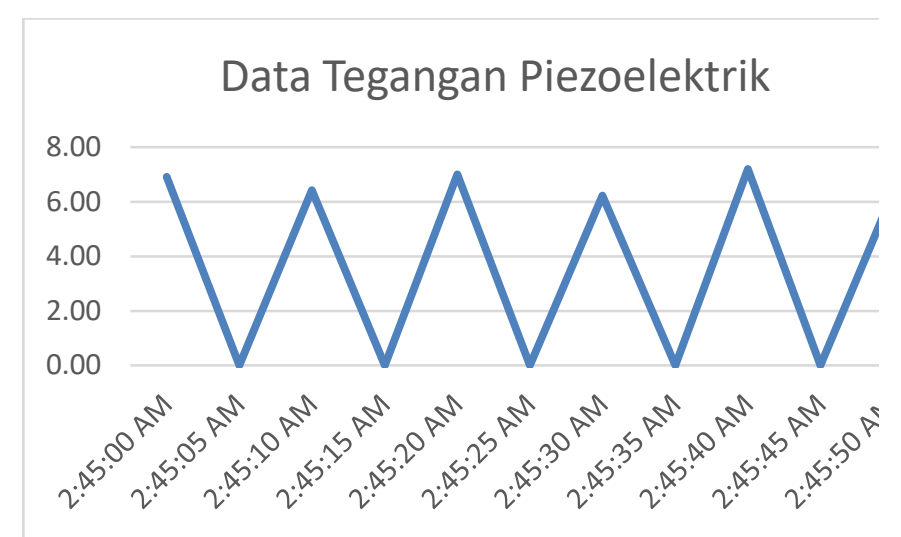

Gambar 13. Data Tegangan Piezoelektrik

\section{KESIMPULAN}

Berdasarkan perancangan sistem, pembuatan alat serta dari pengujian-pengujian yang telah dilakukan dapat disimpulkan bahwa piezoelektrik untuk mencharging baterai masih bleum memadai karna tegangan yang dikeluarkan masih belum stabil dan mungkin perlu dilakukan penelitian lebih lanjut untuk dapat membuat mekanik piezoelektrik yang lebih stabil dan cukup memadai untuk pengisian baterai

\section{REFERENSI}

[1] Ahmad Hendriawan, D. C. (2014). PIEZOELECTRIC SEBAGAI ALTERNATIF CATU DAYA TAMBAHAN PADA MOBIL LISTRIK . Inovtek, 26.

[2] Fahad Hermawan Widodo, M. R. (2017). System Design And Monitoring Current Power Generated by Piezoelectric Floor for Battery Charging . e-Proceeding of Engineering, 795.

[3] Harriyantu, A. R. (2015). STUDI ANALISIS GELOMBANG TEGANGAN PIEZOELEKTRIK.

[4] R. Gustav Rinaldi, M. A. (2018). PERBANDINGAN PENGISIAN KAPASITOR OLEH PIEZOELEKTRIK DENGAN BATEREI . Prosiding SNFA, 2548.

[5] Yulia.E ,Ekawati.E, Nugraha (2016) POLISI TIDUR PIEZOELEKTRIK SEBAGAI PEMBANGKIT LISTRIK DENGAN MEMANFAATKAN ENERGI MEKANAIK KENDARAAN BERMOTOR , j.Oto,Ktrl.Inst Vol 8 No 1 ,ISSN : 2085-2517 